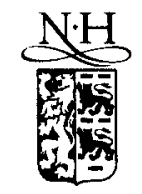

ELSEVIER

Intern. J. of Research in Marketing 13 (1996) 331-343

International Journal of

Research in

Marketing

\title{
The impact of the quality of a marketing decision support system: An experimental study
}

\author{
Gerrit H. van Bruggen *, Ale Smidts, Berend Wierenga \\ Rotterdam School of Management, Department of Marketing Management, Erasmus Unicersity Rotterdam, P.O. Box I738. 3000 DR \\ Rotterdam, The Netherlands
}

Received 1 October 1994: accepted 4 June 1996

\begin{abstract}
In this paper we present the results of an experimental study of the impact of the quality of a marketing decision support system (MDSS). The experiment was conducted in the MARKSTRAT environment. The quality of an MDSS was operationalized as the predictive precision of its simulation models. The results show that marketing decision-makers using a high-quality MDSS outperform marketing decision-makers using a medium-quality MDSS. The superior performance with the high-quality MDSS was obtained for both low and high time-pressure.
\end{abstract}

Keywords: Decision support; System quality; Laboratory experiment; MARKSTRAT

\section{Introduction}

Since the early 1960s the literature of marketing science has been enriched by a great number of publications on marketing decision support systems (MDSS). Most of this literature focuses on the development of these decision aids, more specifically on marketing modelling (Montgomery and Urban, 1969; Naert and Leeflang, 1978; Lilien et al., 1992).

Although the aim of MDSS ${ }^{1}$ is to increase the effectiveness of decision-makers, little attention has been paid to the issue of whether these systems really improve performance. The two best-known

\footnotetext{
Corresponding author. Phone: $++31-10-4082258$; fax: ++ 3]-10-2120544; e-mail: GBRUGGEN@FAC.FBK.EUR.NL

${ }^{1}$ Henceforth, the abbreviation MDSS is used for both Marketing Decision Support System (singular) and Marketing Decision Support Systems (plural).
}

studies of the effectiveness of MDSS are the laboratory experiments performed by Chakravarti et al. (1979) and McIntyre (1982). Chakravarti et al. (1979) found that the use of ADBUDG did not improve the quality of advertising decisions and in fact led to poorer decisions. McIntyre (1982) reported, contrary to the results of Chakravarti et al. (1979), that decision calculus models can produce better decisions. Thus, the results of the two previous empirical studies of the effectiveness of MDSS are mixed.

We propose that the extent to which an MDSS affects the performance of decision-makers using the system is dependent on four categories of variables: (i) the MDSS itself, (ii) the marketing decisionmaker, (iii) the marketing problem, and (iv) the decision-environment.

In studies of the effectiveness of MDSS, the emphasis has been on use versus non-use of MDSS and how this influenced the performance of 
decision-makers. This is an all-or-none perspective on category $(i)$. In category (ii), decision-maker variables, McIntyre (1982) analyzed the effects of variables such as mathematical ability and cognitive style, and Zinkhan et al. (1987) studied the effects of risk aversion, cognitive differentiation, involvement, age, and both managerial and DSS experience. In category (iii), problem characteristics, McIntyre (1982) investigated the influence of problem size on the effectiveness of MDSS. Finally, category (iv), the decision-environment also was studied by McIntyre (1982) in examining the influence of the noise level in the environment on the effectiveness of an MDSS.

So far, to our knowledge, the influence of characteristics of the MDSS itself (category (i)) on the performance of marketing decision-makers has not been studied, even though one might expect the quality of the MDSS to have a major effect. In this paper we compare the effects of two different MDSS, a medium-quality system and a high-quality system. We focus on the following research question: does the quality of a Marketing Decision Support System influence its effects, and does this influence depend on the time-pressure under which the decisions have to be made?

The effect of the MDSS is operationalized as two sets of variables: objective and subjective. The performance of marketing decision-makers and the intensity with which the systems are used are measured objectively. The subjective measures concern the confidence decision-makers show in the decisions they made and the perceived usefulness of the system that was used. Both variables describe the psychological effects of the quality of the MDSS.

The effects of the quality of the MDSS are investigated for both low time-pressure and high-time pressure conditions. Marketing decision-makers often have to operate under a substantial time-pressure; for example, the availability of scanner data on a repetitive basis makes it necessary to make decisions very frequently. We expect time-pressure may possibly eliminate the performance advantage of a highquality MDSS.

We carried out a laboratory experiment in a simulated marketing environment, the MARKSTRAT environment (Larréché and Gatignon, 1990), which can be characterized as comprehensive and dynamic.
MARKSTRAT is considered a realistic environment for studying marketing decision-making and has been extensively used in previous studies (Hogarth and Makridakis, 1981; Glazer et al., 1987; Glazer et al., 1989; Curren et al., 1992; Glazer et al., 1992; Glazer and Weiss, 1993).

The organization of this paper is as follows: in Section 2 , we describe the theory relating to the main variables, leading to their hypothesized effects; in Section 3, the methodology of the study is described; the results of our study are presented in Section 4; and finally in Section 5 we discuss our most important findings and their implications.

\section{Hypotheses}

\subsection{Quality of the MDSS}

It seems reasonable to expect that better-quality MDSS will have a more positive impact on the performance of marketing decision-makers than systems with lower quality. Here we define the quality of an MDSS as the predictive precision of its simulation models. We look at the effects of two MDSS, which differ in the quality of their simulation models. The first MDSS makes predictions, for the outcomes of marketing-mix programs, which show a reasonable precision (the 'medium-quality' MDSS). The second MDSS has higher predictive precision (the 'high-quality' MDSS).

We expect that since the high-quality MDSS provides more accurate predictions than the medium-quality MDSS, it will be superior in improving performance. We also expect that the high-quality MDSS will be used more intensively than the medium-quality MDSS. This latter expectation is supported by the Deshpandé and Zaltman (1982) finding that increasing the quality of market research enhances its use. Further, since the high-quality MDSS produces predictions that deviate less from the actual results than the medium-quality MDSS, we expect that the highquality MDSS increase decision-confidence and will be perceived as more useful than the medium-quality MDSS.

In order to test the hypotheses, we compare the results of both groups of MDSS decision-makers (users of the medium-quality MDSS and users of the 
high-quality MDSS) with the results of decisionmakers who did not use any MDSS.

We hypothesize that:

H.1a. Decision-makers using the high-quality MDSS will outperform decision-makers using the medium-quality MDSS. Decision-makers using the medium-quality MDSS will outperform the unaided decision-makers.

$H .1 b$. Decision-makers using the high-quality MDSS will use the system more intensively than decision-makers using the medium-quality MDSS.

H.lc. Decision-makers using the high-quality MDSS will show more decision-confidence than decision-makers using the medium-quality MDSS. Decision-makers using the medium-quality MDSS will show more decision-confidence than unaided decision-makers.

H.Id. Decision-makers using the high-quality MDSS will perceive their system as more useful than decision-makers using the medium-quality MDSS.

\subsection{Time-pressure}

Decision-making under time-pressure is definable as a situation in which the amount of time does not suffice to find a solution to the particular problem at hand or to reach the most effective result possible (Bronner, 1973). According to Rothstein (1986). time-pressure causes utilization of less information, which produces an overall performance decrement. Time-pressure also should affect information gathering and processing. Wright (1974), for example, found that high time-pressured subjects take fewer dimensions into account when evaluating cars.

To be able to maximally exploit the opportunities a high-quality MDSS offers, a decision-maker needs enough time. Under high time-pressure, both the medium-quality MDSS and the high-quality MDSS provide the decision-maker with sufficient if not optimal information on alternative marketing mixes. However, when there is enough time, the high-quality MDSS can be used to obtain more precise information. which the medium-quality MDSS is not able to deliver. Therefore, we expect that (positive) dif- ferences with respect to both the objective and the subjective measures between users of the high-quality MDSS and users of the medium-quality MDSS will be larger when decision-makers operate under low time-pressure, relative to working under high time-pressure.

We hypothesize that:

H.2a. Under low time-pressure the difference in performance between marketing decision-makers using the high-quality MDSS and marketing decisionmakers using the medium-quality MDSS will be larger than under high time-pressure.

$H .2 b$. Under low time-pressure the difference in the intensity of use between the high-quality MDSS and the medium-quality MDSS will be larger than under high time-pressure.

H.2c. Under low time-pressure the difference in decision-confidence between users of the high-quality MDSS and users of the medium-quality MDSS will be larger than under high time pressure.

$H .2 d$. Under low time-pressure the difference in perceived usefulness between the high-quality MDSS and the medium-quality MDSS will be larger than under high time pressure.

\section{Methodology}

\subsection{Design}

The experimental variables in our study were quality of the MDSS (QUALITY) and time-pressure (TIPR). QUALITY has three levels: no MDSS, medium-quality MDSS, and high-quality MDSS. TIPR has two levels: low time-pressure and high time-pressure. In the $3 * 2$ factorial design, six experimental groups, consisting of 20 subjects each, were created.

\subsection{Subjects}

Participants in the experiment were 120 masterlevel students in business administration or business economics. The selected students all had passed a 
substantial number of courses in marketing. Subjects were assigned randomly to the six experimental groups. No systematic differences appeared in the groups' analytical capabilities as measured by the Embedded Figures Test (Witkin et al., 1971) ( $F=$ $0.755, p=0.584$ ) or experience in working with computers as measured by the mean number of weekly hours they used a computer $(F=0.521$, $p=0.750$ ).

\subsection{Experimental task}

The subjects adopted the role of marketing decision-makers in the MARKSTRAT world. MARKSTRAT provides an environment in which a fixed number of firms (five) compete, using a large set of marketing instruments in markets with heterogeneous consumer preferences (for a complete description see Gatignon (1987) and Larréché and Gatignon (1990)). Specifically, the subjects were the marketing decision-makers of MARKSTRAT Company Two. This company was marketing two brands, called SEMI and SELF, of a consumer-durable electronic product. The objective given to the decision-makers was to maximize the total market-share of their company. They were told, however, that "profits are also very important because the profit in one period determines the marketing budget in the next". To obtain a certain market-share, the decision-makers had to make decisions concerning the advertising budget, the percentage of the advertising budget allocated to advertising research, and the price and the quantity of products to be produced. These decisions had to be made for both brands: SEMI and SELF. Furthermore, in each period decisions had to be made on the sales force size and the allocation of this sales force over the distribution channels. The market-share obtained for both brands was a function of their own decisions, the decisions of competitors, and environmental factors in the MARKSTRAT world.

Subjects had to make their decisions for four consecutive periods. To avoid an 'end-of-game' effect the subjects were not told in advance the number of periods to be played.

In addition to the company of the decision-maker, four other competitive companies were active in the industry. Each of these four companies was market- ing two brands. These four companies were "phantom' companies. All decisions for these phantom companies were programmed by the experimenter in advance. The competitive behavior can be characterized as rational and is in conformity with the principles of the Growth-Share Matrix of the Boston Consulting Group (Aaker, 1992): brands with profitpotential were provided with more marketing support than less promising brands, which were treated as cash-cows. The phantom company approach means that each subject faced the same starting situation and the same competitors. The subjects did not compete with each other which makes the performance of subjects independent of other subjects. Consequently, the results of the subjects are comparable.

\subsection{Game information}

In each period all decision-makers received the standard MARKSTRAT computer output. In addition to this information, the decision-makers operating in the MDSS conditions had an MDSS at their disposal. The MDSS consisted of both a data base and a model base. The MDSS enabled the decisionmakers to investigate the effects of a number of alternative marketing actions by performing 'whatif' analyses. For this purpose the MDSS contained a simulation model. Input for the data base of the MDSS in each period were marketing research data, financial data concerning the company, and data about general economic conditions. These data were generated by the MARKSTRAT-program. To perform what-if analyses, the user of the system had to enter self-chosen values for the decision-variables for the brands SEMI and SELF. The MDSS then predicted the values of: the number of distributors in each channel, brand awareness, the amount of sales, the net marketing contribution (profit).

The users of the MDSS were allowed to make as many simulations as they wanted in order to help them design a marketing plan. The MDSS also had the option of presenting graphs for the relationship between advertising expenditures and brand awareness. Graphics were also available for the relationship between distribution efforts and the number of distributors for a brand. 


\subsection{Overall measurement plan}

For each subject, market-share (SHARE) was measured as the performance variable. In total four periods were played. Therefore, we have four (repeated) measurements for SHARE. The number of simulations (SIMUL) made with both the mediumquality and the high-quality MDSS was counted as a measure for the intensity with which the two MDSS were used. SIMUL was measured in all four decision-making periods for the decision-makers having an MDSS at their disposal. Decision-confidence (CONFIDENCE) was measured twice for all subjects: after the subjects made decisions in the second and fourth periods. Finally, the perceived usefulness of the MDSS (USEFUL) was measured twice: after making decisions in the second and fourth periods. USEFUL was measured only for decision-makers who used an MDSS. The measures of these variables were as follows.

\subsection{Measures}

\subsubsection{Objective variables}

1. Market Share (SHARE). The performance of the subjects was measured by the level of the market-share and profit they obtained for the two brands combined. Analyses were performed for both market-share and profit. Since the results in our study were very similar for these two variables $(r=0.89$, $p<0.000$ ), we report only the market-share results. SHARE was calculated as the combined market share (in volume) of the brands SEMI and SELF.

2. Number of Simulations (SIMUL). The intensity with which the two MDSS were used was measured by the number of 'what-if' simulations. Each time the decision-maker used the MDSS to investigate the consequences of a certain marketing action, it was counted as a simulation.

\subsubsection{Subjective variables}

1. Decision-Confidence (CONFIDENCE). To measure the confidence decision-makers showed in their decisions, we developed a CONFIDENCE-scale in which subjects were asked to rate five items (see Appendix A for the wording of the items). The CONFIDENCE-scale appeared to be uni-dimen- sional and attained a Cronbach alpha reliability of 0.73 .

2. Perceived Usefulness of the MDSS (USEFUL). To measure how useful the subjects perceived the MDSS to be, we adopted the USEFUL-scale developed and validated by Davis (1989) (see also Adams et al., 1992; Hendrickson et al., 1993). On six items, subjects were asked to assess how useful they perceived the MDSS in making decisions (see Appendix B). The USEFUL-scale was also uni-dimensional and attained a Cronbach alpha reliability of 0.89 .

\subsubsection{Independent variables}

1. Quality of a Marketing Decision Support System (QUALITY). For the QUALITY factor, three different modes of marketing decision support were applied: no MDSS, medium-quality MDSS and high-quality MDSS. In the non-MDSS situation subjects had only the standard MARKSTRAT information at their disposal. The quality-difference between the two MDSS were the following:

Medium-quality MDSS. The decision-makers operating in the medium-quality MDSS condition had an MDSS at their disposal which showed a mean absolute percentage error (MAPE) in its forecasts of $23 \%$ (standard deviation $16 \%$ ) for the simulation of 100 realistic marketing-mix combinations. ${ }^{2}$ High-Quality MDSS. The simulation model of the high-quality MDSS gave very good predictions for the various phenomena in the market. In a simulation of the same 100 marketing-mix programs mentioned above, the MAPE was 3\% (standard deviation $2.6 \%$ ). So the MAPE of the high-quality MDSS was set exactly 20 percentage-points lower than the MAPE of the medium-quality MDSS. We chose such a high level because the use of such an accurate MDSS gives us an idea of the potential a very good MDSS has.

\footnotetext{
'Not very much is known about the predictive power of marketing models used in real-life settings. This makes it difficult to assess what a realistic level of the predictive power of an MDSS is. However, in the field of time-series models, Wheelwright and Makridakis (1985) report an average MAPE of 24 time-series methods which was $22.1 \%$. So the forecasting error of $23 \%$ for our medium-quality MDSS is comparable with the MAPE of these time-series methods.
} 
Table 1

Results of the four ANOVAs

\begin{tabular}{|c|c|c|c|c|c|}
\hline & SS & DF & MS & $F$ & Sig of $F$ \\
\hline \multicolumn{6}{|l|}{ SHARE (between subjects) } \\
\hline RESIDUAL & 9759.81 & 114 & 85.61 & & \\
\hline QUALITY & 2287.15 & 2 & 1143.58 & 13.36 & 0.000 \\
\hline TIPR & 532.99 & 1 & 532.99 & 6.23 & 0.014 \\
\hline QUALITY * TIPR & 302.95 & 2 & 151.47 & 1.77 & 0.175 \\
\hline \multicolumn{6}{|l|}{ SHARE (within subjects) } \\
\hline RESIDUAL & 4028.50 & 342 & 11.78 & & \\
\hline Huynh Feldt ${ }^{a}$ & & 236.23 & & & \\
\hline PERI & 914.77 & 3 & 304.92 & 25.89 & 0.000 \\
\hline Huynh Feldt & & 2.07 & & 25.89 & 0.000 \\
\hline QUALITY * PERI & 57.47 & 6 & 9.58 & 0.81 & 0.560 \\
\hline Huynh Feldt & & 4.14 & & 0.81 & 0.522 \\
\hline TIPR $*$ PERI & 14.58 & 3 & 4.86 & 0.41 & 0.744 \\
\hline Huynh Feldt & & 2.07 & & 0.41 & 0.670 \\
\hline QUALITY $*$ TIPR * PERI & 49.50 & 6 & 8.25 & 0.70 & 0.650 \\
\hline Huynh Feldt & & 4.14 & & 0.70 & 0.597 \\
\hline \multicolumn{6}{|l|}{ SIMUL (between subjects) } \\
\hline RESIDUAL & 28076.73 & 76 & 369.43 & & \\
\hline QUALITY & 120.05 & 1 & 120.05 & 0.32 & 0.570 \\
\hline TIPR & 5248.80 & 1 & 5248.80 & 14.21 & 0.000 \\
\hline QUALITY * TIPR & 0.61 & 1 & 0.61 & 0.00 & 0.968 \\
\hline \multicolumn{6}{|l|}{ SIMUL (within subjects) } \\
\hline RESIDUAL & 15779.07 & 228 & 69.21 & & \\
\hline Huynh Feldt & & 190.40 & & & \\
\hline PERI & 841.41 & 3 & 280.47 & 4.05 & 0.008 \\
\hline Huynh Feldt & & 2.51 & & 4.05 & 0.012 \\
\hline QUALITY * PERI & 1623.38 & 3 & 541.13 & 7.82 & 0.000 \\
\hline Huynh Feldt & & 2.51 & & 7.82 & 0.000 \\
\hline TIPR * PERI & 428.32 & 3 & 142.77 & 2.06 & 0.106 \\
\hline Huynh Feldt & & 2.51 & & 2.06 & 0.118 \\
\hline QUALITY * TIPR * PERI & 29.31 & 3 & 9.77 & 0.14 & 0.935 \\
\hline Huynh Feldt & & 2.51 & & 0.14 & 0.909 \\
\hline \multicolumn{6}{|c|}{ CONFIDENCE (between subjects) } \\
\hline RESIDUAL & 135.43 & 114 & 1.19 & & \\
\hline QUALITY & 1.63 & 2 & 0.81 & 0.68 & 0.507 \\
\hline TIPR & 2.30 & 1 & 2.30 & 1.93 & 0.167 \\
\hline QUALITY * TIPR & 0.02 & 2 & 0.01 & 0.01 & 0.993 \\
\hline \multicolumn{6}{|c|}{ CONFIDENCE (within subjects) } \\
\hline RESIDUAL & 35.93 & 114 & 0.32 & & \\
\hline PERI & 7.80 & 1 & 7.80 & 24.76 & 0.000 \\
\hline QUALITY * PERI & 0.63 & 2 & 0.32 & 1.00 & 0.371 \\
\hline TIPR $*$ PERI & 0.01 & 1 & 0.01 & 0.03 & 0.869 \\
\hline QUALITY * TIPR * PERI & 0.17 & 2 & 0.08 & 0.26 & 0.768 \\
\hline \multicolumn{6}{|l|}{ USEFUL (between subjects) } \\
\hline RESIDUAL & 82.15 & 76 & 1.08 & & \\
\hline QUALITY & 0.30 & 1 & 0.30 & 0.28 & 0.600 \\
\hline TIPR & 0.87 & 1 & 0.87 & 0.80 & 0.374 \\
\hline QUALITY*TIPR & 4.85 & 1 & 4.85 & 4.49 & 0.037 \\
\hline
\end{tabular}


Table I (continued)

\begin{tabular}{|c|c|c|c|c|c|}
\hline & SS & DF & MS & $F$ & Sig of $F$ \\
\hline \multicolumn{6}{|l|}{ USEFUL (within subjects) } \\
\hline RESIDUAL & 7.51 & 76 & 0.10 & & \\
\hline PERI & 0.01 & 1 & 0.01 & 0.13 & 0.718 \\
\hline QUALITY * PERI & 0.00 & 1 & 0.00 & 0.02 & 0.878 \\
\hline TIPR $*$ PERI & 0.00 & 1 & 0.00 & 0.00 & 0.972 \\
\hline QUALITY $*$ TIPR $*$ PERI & 0.06 & 1 & 0.06 & 0.62 & 0.433 \\
\hline
\end{tabular}

All levels of significance of within-subject effects were corrected for the violation of the assumption of the homogeneity of variance for within-subjects. The Huynh Feldt correction (Tabachnick and Fideli, 1989) was used for this purpose.

2. Time-Pressure (TIPR). The TIPR factor had two levels: one group of subjects was working under low time-pressure and a second group of subjects was working under high time-pressure. The maximum amount of time needed for marketing decision-makers to make decisions in the low timepressure condition was determined after conducting a pilot study. The maximum allowable amount of time in the four consecutive periods was $40,25,25$, and 25 minutes per period, respectively, with the longer initial period to allow warmup and learning. The amount of time available for subjects in the high time-pressure condition was made dependent on the actual amount of time used by decision-makers working under low time-pressure. Subjects in high time-pressure groups received $75 \%$ of the median of the amounts of actual decision-making time of the decision-makers in the respective low time-pressure group. A manipulation check was conducted by means of a perceived time-pressure (PTIPR)-scale (see Appendix C). ANOVA showed that the timepressure manipulation was successful $(F=16.96$, $p<0.001)$. Subjects in the high time-pressure conditions perceived more time-pressure than subjects in the low time-pressure conditions.

\section{Results}

For each of the four dependent variables (marketshare, number of simulations, decision-confidence, and perceived usefulness), we analyzed the effects of the quality of the MDSS, time-pressure and the interaction between these two factors. To test the effects over the four periods (the game-period number will be denoted as PERI), we employed a re- peated-measures ANOVA design (Winer, 1971). The form of this general model for each of the four dependent variables was:

$$
\begin{aligned}
& \text { SHARE } \\
& \text { SIMUL }=\mu+\alpha_{1} \text { QUALITY }+\alpha_{2} \text { TIPR } \\
& \text { USEFUL } \\
& \begin{array}{l}
+\alpha_{3} \text { PERI }+\alpha_{4} \text { QUALITY } \\
* \text { TIPR }+\alpha_{5} \text { QUALITY } \\
* \text { PERI }+\alpha_{6} \text { TIPR } * \text { PERI } \\
+\alpha_{7} \text { QUALITY } * \text { TIPR } * \text { PERI } \\
+\epsilon .
\end{array}
\end{aligned}
$$

A single MANOVA could not be not conducted since not all dependent variables were measured for all subjects in all of the four periods. Therefore, four separate ANOVAs were conducted. The results of these ANOVAs are presented in Table 1 and will be described in the remainder of this section. When significant effects were found, separate comparison tests were performed to detect between which levels of the variables these differences existed.

\subsection{Market-share (Hypotheses H.la and H.2a)}

The results for SHARE are presented in Table 2. A significant difference in SHARE resulted for the three levels of QUALITY $(F=13.36, p<0.001){ }^{3}$ Separate comparison tests showed that marketing

\footnotetext{
${ }^{3}$ All significance levels presented in this paper are two-tailed. For the interpretation of the p-values of the separate comparisons between the three levels of the QUALITY variable we took the Bonferroni Inequality (Stevens, 1986) into account. This means that more conservative critical values ((overall $\alpha) / 3$ ) were used.
} 
Table 2

Mean market shares (in percentages) for the six experimental groups in the four periods and averaged over the four periods (at bottom of cells) ${ }^{2}$

\begin{tabular}{|c|c|c|c|c|}
\hline \multirow{2}{*}{$\begin{array}{l}\text { Marketing decision } \\
\text { support system }\end{array}$} & \multicolumn{4}{|c|}{ Time-pressure } \\
\hline & \multicolumn{2}{|c|}{ Low } & \multicolumn{2}{|c|}{ High } \\
\hline \multirow[t]{6}{*}{ No MDSS (control group) } & \multicolumn{2}{|c|}{ Group 1} & \multicolumn{2}{|c|}{ Group 2} \\
\hline & 1. & $\begin{array}{l}17.42 \\
(2.28)\end{array}$ & 1. & $\begin{array}{l}17.15 \\
(1.99)\end{array}$ \\
\hline & 2. & $\begin{array}{l}17.49 \\
(3.76)\end{array}$ & 2. & $\begin{array}{l}16.54 \\
(3.07)\end{array}$ \\
\hline & 3. & $\begin{array}{l}19.30 \\
(5.61)\end{array}$ & 3. & $\begin{array}{l}17.65 \\
(4.48)\end{array}$ \\
\hline & 4. & $\begin{array}{l}21.70 \\
(6.83)\end{array}$ & 4. & $\begin{array}{l}20.30 \\
(4.84)\end{array}$ \\
\hline & & $\begin{array}{l}18.98 \\
(4.09)\end{array}$ & & $\begin{array}{l}17.91 \\
(3.22)\end{array}$ \\
\hline \multirow[t]{6}{*}{ MDSS (medium-quality) } & \multicolumn{2}{|c|}{ Group 3} & \multicolumn{2}{|c|}{ Group 4} \\
\hline & 1. & $\begin{array}{l}21.73 \\
(4.24)\end{array}$ & 1. & $\begin{array}{l}20.19 \\
(4.47)\end{array}$ \\
\hline & 2. & $\begin{array}{c}9.69 \\
(5.91)\end{array}$ & 2. & $\begin{array}{l}19.05 \\
(5.65)\end{array}$ \\
\hline & 3. & $\begin{array}{c}20.98 \\
(6.98)\end{array}$ & 3. & $\begin{array}{l}20.14 \\
(6.73)\end{array}$ \\
\hline & 4. & $\begin{array}{l}22.84 \\
(6.23)\end{array}$ & 4. & $\begin{array}{l}22.25 \\
(6.60)\end{array}$ \\
\hline & & $\begin{array}{l}21.31 \\
(5.03)\end{array}$ & & $\begin{array}{l}20.41 \\
(5.34)\end{array}$ \\
\hline \multirow[t]{6}{*}{ MDSS (high-quality) } & \multicolumn{2}{|c|}{ Group 5} & \multicolumn{2}{|c|}{ Group 6} \\
\hline & 1. & $\begin{array}{c}24.69 \\
(3.29)\end{array}$ & 1. & $\begin{array}{l}21.42 \\
(3.90)\end{array}$ \\
\hline & 2. & $\begin{array}{l}25.40 \\
(5.60)\end{array}$ & 2. & $\begin{array}{l}19.35 \\
(5.36)\end{array}$ \\
\hline & 3. & $\begin{array}{l}25.62 \\
(6.93)\end{array}$ & 3. & $\begin{array}{l}21.10 \\
(6.31)\end{array}$ \\
\hline & 4. & $\begin{array}{l}28.13 \\
(7.45)\end{array}$ & 4. & $\begin{array}{l}24.56 \\
(7.81)\end{array}$ \\
\hline & & $\begin{array}{l}25.96 \\
(4.85)\end{array}$ & & $\begin{array}{l}21.61 \\
(4.90)\end{array}$ \\
\hline
\end{tabular}

a Standard deviations in parentheses. Each group: $n=20$.

decision-makers using the high-quality MDSS outperformed decision-makers using the medium-quality MDSS $(F=7.48, p=0.008)$, while decisionmakers using the medium-quality MDSS outperform the decision-makers not using an MDSS at all $(F=$
5.54, $p=0.021)$. These results support hypothesis H.la.

Overall, marketing decision-makers performed worse under high time-pressure than under low time-pressure $(F=6.23, p=0.014)$. However, there was no significant interaction effect between QUALITY and TIPR $(F=1.77, p=0.175)$. This means that the QUALITY-effect does not differ for the two different time-pressure conditions. Therefore, hypothesis H.2a cannot be accepted.

\subsection{Number of simulations (Hypotheses HI.b and $H 2 . b$ )}

The results for SIMUL are presented in Table 3. No main effect of QUALITY shows up ( $F=0.32$,

Table 3

Mean number of simulations for the four experimental groups using an MDSS, in the four periods and averaged over the four periods (at bottom of cells) ${ }^{\text {a }}$

\begin{tabular}{|c|c|c|c|c|}
\hline \multirow{2}{*}{$\begin{array}{l}\text { Marketing decision } \\
\text { support system }\end{array}$} & \multicolumn{4}{|c|}{ Time-pressure } \\
\hline & \multicolumn{2}{|c|}{ Low } & \multicolumn{2}{|c|}{ High } \\
\hline \multirow[t]{6}{*}{ MDSS (medium-quality) } & \multicolumn{2}{|c|}{ Group 3} & \multicolumn{2}{|c|}{ Group 4} \\
\hline & 1. & $\begin{array}{c}23.1 \\
(20.6)\end{array}$ & 1. & $\begin{array}{c}17.7 \\
(15.9)\end{array}$ \\
\hline & 2. & $\begin{array}{c}17.4 \\
(15.3)\end{array}$ & 2. & $\begin{array}{l}10.2 \\
(7.4)\end{array}$ \\
\hline & 3. & $\begin{array}{c}18.5 \\
(12.1)\end{array}$ & 3. & $\begin{array}{c}8.6 \\
(6.2)\end{array}$ \\
\hline & 4. & $\begin{array}{c}18.6 \\
(12.2)\end{array}$ & 4 & $\begin{array}{c}9.0 \\
(6.1)\end{array}$ \\
\hline & & $\begin{array}{c}19.4 \\
(12.7)\end{array}$ & & $\begin{array}{l}11.4 \\
(7.4)\end{array}$ \\
\hline \multirow[t]{6}{*}{ MDSS (high-quality) } & \multicolumn{2}{|c|}{ Group 5} & \multicolumn{2}{|c|}{ Group 6} \\
\hline & 1. & $\begin{array}{c}17.6 \\
(12.4)\end{array}$ & 1. & $\begin{array}{c}12.8 \\
(11.1)\end{array}$ \\
\hline & 2. & $\begin{array}{c}16.1 \\
(10.6)\end{array}$ & 2. & $\begin{array}{l}10.0 \\
(7.6)\end{array}$ \\
\hline & 3. & $\begin{array}{c}23.3 \\
(13.7)\end{array}$ & 3. & $\begin{array}{l}13.2 \\
(6.8)\end{array}$ \\
\hline & 4. & $\begin{array}{c}25.8 \\
(15.0)\end{array}$ & 4. & $\begin{array}{l}14.0 \\
(8.2)\end{array}$ \\
\hline & & $\begin{array}{c}20.7 \\
(10.7)\end{array}$ & & $\begin{array}{l}12.5 \\
(6.4)\end{array}$ \\
\hline
\end{tabular}

\footnotetext{
Standard deviations in parentheses. Each group: $n=20$.
} 
Table 4

Mean decision-confidence for the six experimental groups, two measures and averaged value (at bottom of cells) ${ }^{a}$

\begin{tabular}{|c|c|c|c|c|}
\hline \multirow{2}{*}{$\begin{array}{l}\text { Marketing decision } \\
\text { support system }\end{array}$} & \multicolumn{4}{|c|}{ Time-pressure } \\
\hline & \multicolumn{2}{|c|}{ Low } & \multicolumn{2}{|c|}{ High } \\
\hline \multirow[t]{4}{*}{ No MDSS (control group) } & \multicolumn{2}{|c|}{ Group 1} & \multicolumn{2}{|c|}{ Group 2} \\
\hline & 2. & $\begin{array}{c}2.04 \\
(0.81)\end{array}$ & 2. & $\begin{array}{c}1.88 \\
(0.76)\end{array}$ \\
\hline & 4. & $\begin{array}{c}2.42 \\
(0.63)\end{array}$ & 4. & $\begin{array}{c}2.14 \\
(0.63)\end{array}$ \\
\hline & & $\begin{array}{l}2.23 \\
(0.61)\end{array}$ & & $\begin{array}{c}2.01 \\
(0.70)\end{array}$ \\
\hline \multirow[t]{4}{*}{ MDSS (medium-quality) } & \multicolumn{2}{|c|}{ Group 3} & \multicolumn{2}{|c|}{ Group 4} \\
\hline & 2. & $\begin{array}{c}1.91 \\
(0.86)\end{array}$ & 2. & $\begin{array}{c}1.69 \\
(1.05)\end{array}$ \\
\hline & 4. & $\begin{array}{l}2.13 \\
(0.78)\end{array}$ & 4. & $\begin{array}{l}1.99 \\
(1.12)\end{array}$ \\
\hline & & $\begin{array}{l}2.02 \\
(0.75)\end{array}$ & & $\begin{array}{c}1.84 \\
(0.98)\end{array}$ \\
\hline \multirow[t]{4}{*}{ MDSS (high-quality) } & \multicolumn{2}{|c|}{ Group 5} & \multicolumn{2}{|c|}{ Group 6} \\
\hline & 2. & $\begin{array}{l}1.84 \\
(0.81)\end{array}$ & 2. & $\begin{array}{l}1.59 \\
(0.99)\end{array}$ \\
\hline & 4. & $\begin{array}{l}2.28 \\
(0.86)\end{array}$ & 4. & $\begin{array}{l}2.16 \\
(0.89)\end{array}$ \\
\hline & & $\begin{array}{l}2.06 \\
(0.70)\end{array}$ & & $\begin{array}{l}1.88 \\
(0.83)\end{array}$ \\
\hline
\end{tabular}

a Standard deviations in parentheses. Each group: $n=20$. High scores stand for high decision-confidence.

$p=0.570)$. However, there was a significant interaction between QUALITY and PERI $(F=7.82, p<$ 0.001 ). In period 1 the medium-quality MDSS was used more intensively than the high-quality MDSS. However, this difference was not significant $(F=$ $2.26, p=0.137)$. In period 2 there was no difference $(F=0.09, p=0.771)$ in the use of the two systems while in the periods 3 and 4 the high-quality MDSS was used more intensively than the medium-quality MDSS (period 3, $F=3.47, p=0.066$; and period 4, $F=5.15, p=0.026$ ). Therefore, from period 3 onwards, hypothesis H.1b is supported.

There was no interaction between QUALITY and TIPR, implying that the effect of QUALITY on SIMUL was not different for the two time-pressure conditions ( $F=0.01, p=0.968$ ). Accordingly, hypothesis H.2b cannot be accepted. Overall, decisionmakers made fewer simulations under high timepressure than under low time-pressure $(F=14.21$, $p<0.001)$.

\subsection{Decision-confidence (Hypotheses H.Ic and H.2c)}

The results for CONFIDENCE are presented in Table 4. There was no significant difference in CONFIDENCE between the three levels of QUALITY $(F=0.68, p=0.507)$. The results for users of both types of systems were not different even when compared to the unaided decision-makers. Overall, although CONFIDENCE increased between period 2 and period $4(F=24.76, p<0.001)$, this did not differ between the different QUALITY levels ( $F=$ $1.00, p=0.371$ ). Therefore, hypothesis H.1c cannot be accepted.

Although the results in Table 4 show higher decision-confidence for experimental groups making decisions under low time-pressure than for decisionmakers working under high time-pressure, this dif-

Table 5

Mean perceived usefulness of the MDSS for the four experimental groups using an MDSS, two measures and averaged value (at bottom of cells) a

\begin{tabular}{|c|c|c|c|c|}
\hline \multirow{2}{*}{$\begin{array}{l}\text { Marketing decision } \\
\text { support system }\end{array}$} & \multicolumn{4}{|c|}{ Time-pressure } \\
\hline & \multicolumn{2}{|c|}{ Low } & \multicolumn{2}{|c|}{ High } \\
\hline \multirow[t]{4}{*}{ MDSS (medium-quality) } & \multicolumn{2}{|c|}{ Group 3} & \multicolumn{2}{|c|}{ Group 4} \\
\hline & 2. & $\begin{array}{c}3.89 \\
(0.84)\end{array}$ & 2. & $\begin{array}{c}4.43 \\
(0.71)\end{array}$ \\
\hline & 4. & $\begin{array}{c}3.96 \\
(0.66)\end{array}$ & 4. & $\begin{array}{c}4.41 \\
(0.72)\end{array}$ \\
\hline & & $\begin{array}{c}3.92 \\
(0.73)\end{array}$ & & $\begin{array}{c}4.42 \\
(0.68)\end{array}$ \\
\hline \multirow[t]{4}{*}{ MDDS (high quality) } & \multicolumn{2}{|c|}{ Group 5} & \multicolumn{2}{|c|}{ Group 6} \\
\hline & 2. & $\begin{array}{c}4.20 \\
(0.59)\end{array}$ & 2. & $\begin{array}{c}3.96 \\
(0.90)\end{array}$ \\
\hline & 4. & $\begin{array}{c}4.17 \\
(0.70)\end{array}$ & 4. & $\begin{array}{c}4.01 \\
(0.96)\end{array}$ \\
\hline & & $\begin{array}{c}4.18 \\
(0.61)\end{array}$ & & $\begin{array}{c}3.98 \\
(0.89)\end{array}$ \\
\hline
\end{tabular}

a Standard deviations in parentheses. Each group: $n=20$. 


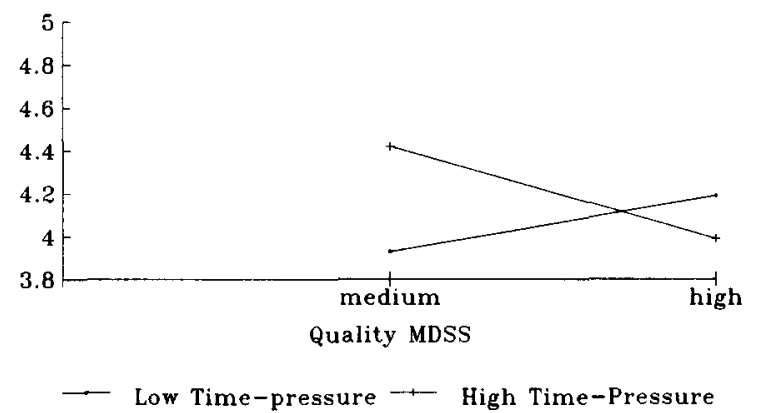

Fig. 1. Perceived usefulness of the MDSS for subjects working under low time-pressure $(n=40)$ and subjects working under high time-pressure $(n=40)$

ference was not significant $(F=1.93, p=0.167)$. This finding did not differ for the different QUALITY levels $(F=0.01, p=0.993)$. Therefore, we cannot accept hypothesis H.2c.

\subsection{Perceived usefulness (Hypotheses H.ld and H.2d)}

Results in Table 5 showed no significant USEFUL-difference as a result of quality differences of the MDSS $(F=0.28, \quad p=0.600)$. Subjects perceived both systems as useful. The average score on the seven-point USEFUL scale was 5.22. Therefore, hypothesis $\mathrm{H} .1 \mathrm{~d}$ cannot be accepted.

As to low and high time-pressure, there was no significant main effect of TIPR $(F=0.80, p=$ 0.374). However, the results in Table 5 and Fig. 1 show an interaction between TIPR and QUALITY $(F=4.49, p=0.037)$. Under low time-pressure, decision-makers tended to perceive the high-quality MDSS as more useful than did those using the medium-quality MDSS although this difference was not significant ( $F=1.52, p=0.225$ ). However, under high time-pressure the medium-quality MDSS was perceived more useful $(F=3.00, p=0.091)$. Both findings mean H.2d cannot be accepted.

\section{Discussion}

In this paper we investigated the impact of the quality of MDSS. In Table 6 we summarize our findings.

We find that decision-makers using the high-qual- ity MDSS outperform those using the medium-quality MDSS, both for low and high time-pressure conditions. This implies that it pays to develop and

Table 6

Summary of findings

\begin{tabular}{|c|c|c|}
\hline Hypoth & heses & Results \\
\hline H.la: & $\begin{array}{l}\text { Decision-makers using the high-qu- } \\
\text { ality MDSS will outperform deci- } \\
\text { sion-makers using the medium-qual- } \\
\text { ity MDSS. Decision-makers using } \\
\text { the medium-quality MDSS will out- } \\
\text { perform the unaided decision- } \\
\text { makers. }\end{array}$ & Accepted \\
\hline
\end{tabular}

Decision-makers using the high-quality MDSS will use the system more intensively than decision-

Accepted for period 3 and 4

H.1b: makers using the medium-quality MDSS

Decision-makers using the high-quality MDSS will show more decision-confidence than decisionmakers using the medium-quality MDSS. Decision-makers using the

H.lc: medium-quality MDSS will show more decision-confidence than unaided decision-makers.

Decision-makers using the high-quality MDSS will perceive their system as more useful than decision-

H.Id: makers using the medium-quality MDSS.

Under low time-pressure the difference in performance between marketing decision-makers using the high-quality MDSS and marketing

H. decision-makers using the mediumquality will be larger than under high time-pressure.

Under low time-pressure the difference in the intensity of use between the high-quality MDSS and the

H.2b: medium-quality MDSS will be larger than under high time-pressure. Under low time-pressure the difference in decision-confidence between users of the high-quality MDSS and users of the medium-quality MDSS

Not accepted, no difference

Not accepted, depends on amount of time-pressure

Not accepted, no impact of timepressure

Not accepted, no impact of timepressure

Not accepted, no impact of timepressure

H.2c: will be larger than under high time pressure.

Under low time-pressure the difference in perceived usefulness between the high-quality MDSS and

Partially accepted
H.2d: the medium-quality MDSS will be larger than under high time pressure. 
use MDSS which show a predictive precision as high as possible, even for decision-makers who operate under high time-pressure. We expect that by using scanning technology more data with a higher quality can be collected and, as a consequence, this enables .... marketing scientists to develop and test models with much more precision than ever before" (Lilien, 1994, p. 13). This implies that the effectiveness of MDSS used in practice can also increase.

We find that the high-quality MDSS is used more intensively than the medium-quality MDSS, although it took some time before this difference appeared. One might question whether the observed better performance of the high-quality MDSS users should be attributed to quality of MDSS as such, or to the fact that the high-quality MDSS is used more frequently. The results show that only in period 3 and period 4 the users of the high-quality MDSS used their system more intensively (conducted more simulations) than users of the medium-quality MDSS. However, because the performance of the users of the high-quality MDSS was higher in all of the four periods, differences in the performance of the users of the two systems can not be explained completely by differences in the use of the system. At least for period 1 and period 2 the difference in performance must have been caused by the quality of the MDSS as such.

Although we did find the hypothesized rank-order in market-share performance corresponding with the QUALITY-levels, no differences in decision-confidence were found. Apparently, high performance does not necessarily lead to high confidence. A factor which in general may improve the CONFIDENCE of subjects is more insight in the way the market reacts on marketing-mix variables. The MDSS in our study were 'black-box' systems, which did not provide the decision-makers with this kind of understanding.

Time-pressure for the decision-maker does affect the perceived usefulness of the systems. The medium-quality MDSS is perceived as more useful than the high-quality MDSS under high time-pressure (although performance is objectively worse). Under low time-pressure both systems are perceived as equally useful, whereas we expected the high-quality MDSS would be more valued with more time. A possible explanation for this finding might be that users of the medium-quality MDSS realize that it is very difficult to predict outcomes of marketing decisions, since they experience a deviation between predictions of their system and the actual results. When they also have to operate under high timepressure, they are confronted with another source of uncertainty. Under these circumstances, subjects might attach more value to having an MDSS available, even when it does not make perfect predictions.

The overall picture of our results shows that QUALITY has more impact on the objective variables of decision-making performance than it has on the subjective variables. McIntyre (1982) reported a similar finding when he found that models, which do increase the effectiveness of the decision, do not necessarily engender a better understanding of market response. Providing decision-makers with a decision-aid, even if it increases effectiveness, does not automatically increase decision-confidence. Apparently, users do not easily recognize the quality of an MDSS. In future research it would be interesting to investigate whether systems which also provide decision-makers with insight in the mechanisms through which their decisions work (e.g., a marketing knowledge-based system), do help decision-makers to become not only more effective but also more confident.

As a consequence of the between-subjects design of our study, the subjects were confronted with only one level of decision support and thus did not have any reference-point. In future research it might be investigated whether in a within-subject research design, in which one subject works with different levels of decision-support (a medium-quality MDSS and a high-quality MDSS), decision-makers do perceive systems which differ in quality as differentially useful. It would be interesting to see whether in such conditions subjects are able to detect quality-differences between MDSS.

The lack of effects on the subjective variables has implications for the diffusion of MDSS in companies. Subjects do not seem to be able to recognize the quality of an MDSS as such. Decision-makers should be provided with information on the usefulness of systems and the opportunities they offer for making better decisions. Wierenga and Oude Ophuis (1994) find communication to be important for the adoption of MDSS. 
In future studies investigating the effects of MDSS it might be considered to start the experiment after all subjects have gained experience in the decisionmaking environment. This way, as an anonymous reviewer suggested, the confounding effect of the fact that by being given an MDSS subjects also get more information, might be avoided.

In our study we investigated the impact of the quality of MDSS on the quality of decisions made by individuals. Many complex decisions in organizations are made by groups of people. In future research it would be interesting to study the impact of so-called Group DSS (DeSantis and Gallupe, 1985) and the effect of the quality of such a system on group marketing-decisions.

Finally, we raise the question of the generalizability of our findings. Three factors can threaten this generalizability. These are the characteristics of the research environment, of the subjects, and of the systems that were used. In this study we used the experimental laboratory approach. As an experimental environment we used MARKSTRAT, which can be characterized as a complete and dynamic marketing-mix decision environment. Research by Kinnear and Klammer (1987) shows that managers, working in diverse industries, believe that MARKSTRAT does reflect a real marketing environment.

In our experiment only business students participated. Locke (1986) states that students and employees appear to respond similarly to goals, feedback, incentives, participation, and so forth, perhaps because the similarities among these subjects (such as in values) are more crucial than their differences. Therefore, we think that students can be used as 'surrogates' for managers in an experiment like the one we conducted, in particular since they are trained in solving marketing problems. A replication of the study with experienced decision-makers as subjects should make clear whether for experienced decision-makers the effects of the quality of an MDSS are different.

The two MDSS were realistic systems which could be applied in real-life settings. The data in the MDSS were typical marketing research data which are available from syndicated marketing research companies. The models were standard econometric models. MDSS (van Campen et al., 1991) have not been widely adopted in real-life situations yet. How- ever, it is our belief that MDSS, like the ones studied here, will be developed for real-life settings too if the worth of high-quality systems continues to be proven and publicized.

\section{Acknowledgements}

The authors are grateful to John Rossiter and two anonymous reviewers for their valuable comments.

Appendix A. Decision-Confidence items (measured on a 'strongly disagree 1-2-3-4-5 strongly agree' scale)

Item

1. In my opinion, I defended my market share as well as I could with the decisions I made

2. I have a great deal of confidence in the decisions I made

3. I don't think it would have been possible to make better decisions than the ones I made over this period

4. I have doubts about the correctness of the decisions I made

5. Given the circumstances, I made the best possible decisions

Cronbach alpha: 0.73

Appendix B. Perceived Usefulness items (measured on a 'likely 1-2-3-4-5-6-7 unlikely' scale)

Item

1. Using the MDSS enabled me to make the decisions more quickly

2. Using the MDSS increased the quality of my decision-making

3. Using the MDSS increased my productivity

4. Using the MDSS enhanced my effectiveness

5. Using the MDSS made it easier to make the decisions

6. I found the MDSS useful for making decisions

Cronbach alpha: 0.89 


\section{Appendix C. Perceived Time-Pressure items (measured on a 'strongly disagree 1-2-3-4-5 strongly agree' scale)}

Item

1. The availability of more decision-making time would have made it possible to make better decisions

2. I felt rushed when playing MARKSTRAT

3. There was insufficient decision-making time to make acceptable decisions

4. There was time-pressure

5. While playing MARKSTRAT, I had sufficient time to make well-considered decisions

6. I had to hurry while playing MARKSTRAT Cronbach alpha: 0.85

\section{References}

Aaker, D.A., 1992. Strategic market Management. New York: Wiley.

Adams, D.A., R.R. Nelson and P.A. Todd, 1992. Perceived usefulness, ease of use, and usage of information technology: A replication. MIS Quarterly (June), 227-247.

Bronner, R., 1973. Entscheidung unter Zeitdruck. Tübingen: Publisher?.

Chakravarti, D., A. Mitchell and R. Staelin, 1979. Judgment based marketing decision models: An experimental investigation of the decision calculus approach. Management Science 25 (3), 251-263.

Curren, M.T., V.S. Folkes and J.H. Steckel, 1992. Explanations for successful marketing decisions: The decision maker's perspective. Journal of Marketing 56, 18-31.

Davis, F.D., 1989. Perceived usefulness, perceived ease of use, and user acceptance of information technology. MIS Quarterly (Sept.), 318-340.

DeSantis, G. and B. Gallupe, 1985. Group decision support systems: A new frontier. Data Base (Winter).

Deshpandé, R. and G. Zaltman, 1982. Factors affecting the use of market research information: A path analysis. Journal of Marketing Research XIX (Feb.), 14-31.

Gatignon, H., 1987. Strategic studies in markstrat. Journal of Business Research 15, 469-480.

Glazer, R., J.H. Steckel and R.S. Winer, 1987. Group process and decision performance in a simulated marketing environment. Journal of Business Research 15, 545-557.

Glazer, R., J.H. Steckel and R.S. Winer, 1989. The formation of key marketing variable expectations and their impact on firm performance: Some experimental evidence. Marketing Science 8 (1), 18-34.

Glazer, R., J.H. Steckel and R.S. Winer, 1992. Locally rational decision making: The distracting effect of information on managerial performance. Management Science 38 (2), 212226.

Glazer, R. and A.M. Weiss, 1993. Marketing in turbulent environments: Decision processes and the time-sensitivity of information. Journal of Marketing Research XXX (Nov.), 509-521.

Hendrickson, A.R., P.D. Massey and T.P. Cronan, 1993. On the test-retest reliability of perceived usefulness and perceived ease of use scales. MIS Quarterly (June), 227--230.

Hogarth, R.M. and S. Makridakis, 1981. The value of decision making in a complex environment: An experimental approach. Management Science 27 (1), 93-107.

Kinnear, T.C. and S.K. Klammer, 1987. Management perspectives on Markstrat. Journal of Business Research 15, 491-501.

Larréché, J.C. and H. Gatignon, 1990. MARKSTRAT2. Redwood City: The Scientific Press.

Lilien, G.L., 1994. Marketing models: Past, present and future. In: G. Laurent, G.L. Lilien and B. Pras (Eds.), Research traditions in marketing. Boston, MA: Kluwer Academic Publishers.

Lilien, G.L., P. Kotler and K.S. Moorthy, 1992. Marketing models. Englewood Cliffs, NJ: Prentice Hall.

Locke, E.A., 1986. Generalizing from laboratory to field settings, Research findings from industrial-organizational psychology, organizational behavior, and human resource management. Lexington, MA: Lexington Books.

McIntyre, S.H., 1982. An experimental study of the impact of judgment-based marketing models. Management Science 28 (1), 17-33.

Montgomery, D.B. and G.L. Urban, 1969. Management science in marketing. Englewood Cliffs, NJ: Prentice Hall.

Naert, P. and P. Leeflang, 1978. Building implementable marketing models. Leiden: Martinus Nijhoff.

Rothstein, H.G., 1986. The effects of time pressure on judgment in multiple cue probability learning. Organizational Behavior and Human Decision Processes 37, 83-92.

Stevens, J., 1986. Applied multivariate statistics for the social sciences. Hillsdale, NJ: Lawrence Erlbaum.

van Campen, P.A.F.M., K.R.E. Huizingh, P.A.M. Oude Ophuis and B. Wierenga, 1991. Marketing decision support systemen bij Nederlandse bedrijven. Delft: Eburon.

Wheelwright, S.C. and S. Makridakis, 1985. Forecasting methods for management, 4th edition. New York: Wiley.

Wierenga, B. and P. Oude Ophuis, 1994. Marketing decision support systems: Adoption, sophistication, use and satisfaction, Management report series, no. 181. Rotterdam School of Management, Erasmus University Rotterdam.

Winer, B.J., 1971. Statistical principles in experimental design. New York: McGraw-Hill.

Witkin, H.A., P.K. Oltman, E. Raskin and S.A. Karp, 1971. A manual for the embedded figures tests. Palo Alto, CA: Consulting Psychologists Press, Inc.

Wright, P., 1974. The harassed decision maker: Time pressure, distractions and the use of evidence. Journal of Applied Psychology 59 (5), 555-561.

Zinkhan, G.M., E.A. Joachimsthaler and T.C. Kinnear, 1987. Individual differences and marketing decision support system usage and satisfaction. Journal of Marketing Research XXIV, $208-214$. 